\title{
A participação de Minas Gerais e do Brasil na cadeia produtiva global do café
}

\section{Minas Gerais and Brazil in the Coffee Global Value Chain}

\author{
Lucio Otavio Seixas Barbosa ${ }^{1}$ \\ Carla Aguilar ${ }^{2}$ \\ Laura Maciel $^{3}$
}

\begin{abstract}
Resumo: Este artigo traça um retrato da participação de Minas Gerais e do Brasil na Cadeia Global de Valor (CGV) do café. A análise se concentra nos anos de 2017 e 2018, a partir, principalmente, de dados de comércio internacional. Para tanto, caracterizam-se as quatro dimensões da CGV: estrutura de insumos e produtos, na qual os traders assumem papel relevante; a distribuição geográfica da produção, que evidencia que os países da América do Sul e da Ásia são os principais exportadores de café em grão; a governança, que sinaliza que os torrefadores detém o comando da cadeia; e o contexto institucional, que revela que Minas Gerais, sendo o principal produtor no Brasil, especializou-se na exportação de café em grão. Adicionalmente, destaca-se que sua produção é realizada majoritariamente por pequenos e médios produtores; a torrefação é concentrada em poucas indústrias; e instituições públicas contribuem para a disseminação de boas práticas de cultivo do café. A análise da CGV do café mostra que os elos inferiores da cadeia adicionam pouco valor ao produto. Portanto, sugerem-se alternativas de reposicionamento (upgrade) para a participação de Minas Gerais: a torrefação e a comercialização de cafés especiais.
\end{abstract}

Palavras-chave: café; Cadeia Global de Valor; upgrade

Abstract: This paper presents the insertion of Minas Gerais and Brazil in the Coffee Global Value Chain (CGVC). The analyses focus on 2017, exploring data from international and regional trade. To this end, it portrays its four dimensions: structure of production, in which traders play an important role; geography of demand and supply, pointing out that countries from South America and Asia exports mainly green coffee; governance, showing that coffee roasters controls the CGV; and the institutional context, revealing that Minas Gerais, which is the largest producer state in Brazil by far, exports mainly green coffee. In addition, small and medium farmers are responsible for the coffee production; the coffee roasting is highly concentrated in few industries; and public institutions help to spill over best growing techniques. The analyses of the CGVC shows that the value added in its first segments is low. Therefore, we identify opportunities to strengthen Minas Gerais position by assuming the roasting process and boosting the special coffee production.

Keywords: coffee, Coffee Global Value Chain, upgrade

\footnotetext{
${ }^{1}$ Graduação em Administração Pública (FJP-MG). Mestrado em economia (UFSC).Doutorado em Economia (Cedeplar/UFMG). Fundação João Pinheiro - MG. E-mail: seixas.lucio@gmail.com

${ }^{2}$ Fundação João Pinheiro - MG

${ }^{3}$ Fundação João Pinheiro - MG
} 
JEL: F10; F13

\section{INTRODUÇÃO}

A história do café em Minas Gerais e no Brasil é bastante rica. Em particular, no início do século XIX, a conexão entre o café e a política foi marcante, dando inclusive nome à política firmada entre as oligarquias estaduais e o governo federal durante a primeira república (política do café-com-leite) ${ }^{4}$.

Atualmente, a realidade é diferente. Desde o fim do sistema estabelecido pelos acordos internacionais de café em 1989, que tinha como objetivo controlar a produção e preços em um contexto global, o setor tem se guiado pelas regras de mercado. Isto é, a produção e o preço são regulados pela oferta e demanda no mercado mundial (MELO, 1993).

De modo geral, os principais atores envolvidos na produção de café são entidades privadas (produtores, torrefadores, varejistas, etc.). No entanto, a participação governamental, seja diretamente na produção ou através de políticas setoriais, é bastante relevante (BAMBER; GUINN; GEREFFI, 2014). Isso significa que o Estado exerce um papel importante na promoção da produção do café. No Brasil, por exemplo, existem instâncias nacionais, tais como o Conselho Deliberativo da Política do Café (CDPC), que pautam o debate sobre a sua cadeia produtiva.

O Brasil é o principal produtor e exportador de café em grão (café verde) no mundo. O estado de Minas Gerais é responsável por mais da metade da produção e mais de $80 \%$ das exportações brasileiras. O país se especializou na produção do café verde, não se integrando aos circuitos superiores da cadeia produtiva, cujo segmento de torrefação é o mais importante. Dessa forma, embora o país seja o principal produtor e exportador, ele ainda importa (em pequena quantidade) café torrado. Adicionalmente, os torrefadores brasileiros não exportam café torrado, em quantidades significativas, nem mesmo para Argentina, que é o principal parceiro comercial brasileiro do Mercado Comum do Sul (Mercosul) ${ }^{5}$.

Nesse contexto, o presente estudo visa retratar as condições atuais da participação de Minas Gerais e do Brasil na cadeia global de valor (CGV) do café. De certa forma, ambas se entrelaçam na medida em que Minas Gerais é, de longe, o principal estado produtor brasileiro. Optou-se por levantar os dados mais recentes sobre o setor cafeeiro, tendo os anos de 2017 e 2018 como referência. Desse modo, a análise se concentra no panorama atual e não na trajetória histórica de desempenho do setor.

O método de análise envolve, em uma primeira etapa, a caracterização da CGV do café a partir de suas quatro dimensões: estrutura de insumos e produtos; geografia da demanda e oferta; governança; e contexto institucional. Essas três primeiras dimensões se referem à caracterização da CGV no contexto global. A quarta e última dimensão trata especificamente do contexto institucional brasileiro e, em particular, do estado de Minas Gerais, em virtude de sua relevância.

A partir dessa caracterização, são levantadas possíveis estratégias para o reposicionamento (upgrade) da inserção de Minas Gerais e, consequentemente, do

\footnotetext{
${ }^{4}$ A política do café-com-leite consistia na alternância de presidentes escolhidos entre os políticos de São Paulo (importante produtor de café) e de Minas Gerais (importante produtor de leite) e maior polo eleitoral do país. Tal política perdurou entre as décadas de 1890 e 1930.

${ }^{5}$ De acordo com os dados do 'Comtrade', a maior parte do café importado pela Argentina vem da Suiça (ver em $<$ https://comtrade.un.org/>).
} 
Brasil nessa cadeia produtiva. Os dois principais caminhos sugeridos são: (i) assumir a etapa de torrefação de café e (ii) aumentar a produção de cafés especiais.

Este estudo utiliza as seguintes fontes de dados: portal do UN Comtrade, no qual se disponibilizam os dados de comércio internacional; portal de estatística de comércio exterior do Brasil, que dispõe informações de exportações e importações por unidade da federação; a Organização Internacional do Café (OIC), que divulga dados de produção de café por país; o Fundo Monetário Internacional, que coleta dados dos preços de commodities; o Instituto Brasileiro de Geografia e Estatística (IBGE), que apresenta informações sobre área plantada e produção de café; e a Fundação João Pinheiro (FJP), que calcula o Produto Interno Bruto (PIB) de Minas Gerais. Além dessas fontes, utilizam-se dados de outras pesquisas e de associações do setor cafeeiro.

A próxima seção apresenta brevemente o conceito da CGV. A seção 3 detalha as dimensões referentes à estrutura de insumos e produtos, à geografia da oferta e da demanda, à governança da CGV do café e o contexto institucional da produção de café em Minas Gerais e no Brasil. A seção 4 propõe estratégias para o reposicionamento (upgrade) na CGV do café. Ao final, apresentam-se as considerações finais, enfatizando a necessidade de o estado mineiro capitanear a articulação política para o reposicionamento do Brasil nessa CGV.

\section{CADEIAS GLOBAIS DE VALOR}

A CGV é utilizada para designar o conjunto de atividades que as empresas desenvolvem desde a concepção de um produto até sua destinação final, incluindo os serviços de pós-venda (GEREFFI; FERNANDEZ-STARK, 2016). Inclui, portanto, diversas fases do processo produtivo, tais como: obtenção de insumos, P\&D, produção, distribuição, comercialização do produto final e serviços de pós-venda. $A$ CGV é global na medida em que existe uma crescente fragmentação e dispersão geográfica da produção, materializadas nos fenômenos de offshoring (contratação de empresas de outros países) e outsourcing (contratação de fornecedores fora da firma). A ideia de valor explicita que cada etapa do processo produtivo, ao longo da cadeia, agrega valor ao produto.

Nesse arranjo, cada uma das fases de produção pode ser realizada por empresas localizadas em qualquer país, desde que elas sejam competitivas. Apesar de dispersas geograficamente, as etapas do processo produtivo são integradas em um sistema global (DEDRICK, KRAEMER e LINDEN, 2010).

De acordo com Gereffi e Fernandez-Stark (2016), a análise das CGVs pode ser decomposta em quatro dimensões, a saber: (i) estrutura de insumos e produtos - que consiste no mapeamento das etapas do processo produtivo e das empresas envolvidas em cada uma delas; (ii) alcance geográfico - que pode ser local, nacional, regional ou global; (iii) estrutura de governança com vistas a identificar a forma pela qual a cadeia é coordenada e controlada; e (iv) contexto institucional - que avalia as condições econômicas, sociais e institucionais em que a cadeia se insere.

Ao longo do tempo a dinâmica da CGV pode se alterar, havendo troca de fornecedores, de parceiros ou mesmo da empresa líder da cadeia. Inclusive, as empresas podem evoluir para nichos econômicos mais rentáveis da cadeia de valor. Esse processo é conhecido como upgrading. Por outro lado, podem existir situações em que a empresa não consegue avançar na CGV (lock-in). Em linhas gerais, o upgrade depende de investimentos substantivos, da adoção de políticas estratégicas e da interação com os sistemas locais de inovação (HUMPHREY; SCHMITZ, 2002). 
A partir do conceito de CGV e de suas quatro dimensões, apresentadas brevemente nesta seção, detalha-se, na próxima seção, o funcionamento da CGV do café, com ênfase ao contexto institucional de Minas Gerais.

\section{Cadeia global de valor do café}

O café é uma commodity estratégica para muitos países em desenvolvimento, incluindo o Brasil, sendo uma das mais comercializadas e valorizadas na economia mundial. De acordo com dados da Organização Internacional do Café (ICO), no período entre 2017 e 2018, os países exportadores produziram em torno de 160 milhões de sacas de café $(60 \mathrm{~kg})$, sendo que quase 120 milhões foram exportadas. A CGV do café inclui diferentes estágios de transformação até a comercialização do produto final.

\section{Estrutura de insumos e produtos}

A estrutura de insumos e produtos contempla cinco segmentos de valor da cadeia, em cada uma delas diferentes atores exercem influência sobre sua dinâmica. O Quadro 1 sistematiza a CGV do café.

Quadro 1: Cadeia Global de Valor do Café

\begin{tabular}{|c|c|c|c|c|c|c|}
\hline & Insumos & Produção & Processamento & Trade & Torrefação & $\begin{array}{l}\text { Comercialização } \\
\text { (varejo) }\end{array}$ \\
\hline \multirow{5}{*}{ 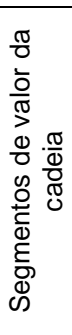 } & mudas & arábica & processo úmido & $\begin{array}{l}\text { negociantes de café } \\
\text { commodity } \\
\text { (tradicional) }\end{array}$ & café torrado & supermercados \\
\hline & fertilizante & robusta & processo seco & $\begin{array}{l}\text { negociantes de } \\
\text { cafés especiais }\end{array}$ & café instantâneo & $\begin{array}{l}\text { serviços de } \\
\text { alimentação }\end{array}$ \\
\hline & spray & & Moagem & & Descafeinação & cafeterias \\
\hline & $\begin{array}{l}\text { terra } \\
\text { trabalho }\end{array}$ & & & & & \\
\hline & $\begin{array}{l}\text { trabaino } \\
\text { assistência } \\
\text { técnica }\end{array}$ & & & & & \\
\hline $\begin{array}{l}0 \\
\frac{1}{0} \\
\frac{9}{<}\end{array}$ & $\begin{array}{l}\text { pequenos } \\
\text { produtores, } \\
\text { comerciantes, } \\
\text { ONGs, } \\
\text { governo }\end{array}$ & $\begin{array}{l}\text { pequenos } \\
\text { produtores, } \\
\text { Estado }\end{array}$ & $\begin{array}{l}\text { pequenos } \\
\text { proprietários, } \\
\text { cooperativas, } \\
\text { Estados, } \\
\text { negociantes }\end{array}$ & $\begin{array}{l}\text { traders (Neumann, } \\
\text { Ecom, Olam), } \\
\text { importadores } \\
\text { certificados, (Green } \\
\text { Moutain), } \\
\text { importadores } \\
\text { diretos } \\
\text { (Intelligentsia) }\end{array}$ & $\begin{array}{l}\text { grandes } \\
\text { torrefadores (Sara } \\
\text { Lee), } \\
\text { produtores de café } \\
\text { instantâneo, } \\
\text { (Nestle), } \\
\text { redes de } \\
\text { cafeterias } \\
\text { (Starbucks), } \\
\text { pequenas } \\
\text { cafeterias }\end{array}$ & $\begin{array}{l}\text { supermercados, } \\
\text { restaurantes } \\
\text { (McDonalds), } \\
\text { cafeterias } \\
\text { (Starbucks) }\end{array}$ \\
\hline
\end{tabular}

Fonte: Adaptado de Bamber, Guinn e Gereffi (2014).

Cada etapa da CGV do café pode ser caracterizada da seguinte forma:

(i) insumos: a produção de café requer diversos insumos, incluindo insumos físicos (mudas, fertilizantes e sprays), terra e trabalho. A qualidade dos insumos pode determinar a destinação final do produto (e.g., produções de cafés certificados como orgânicos). Frequentemente, nessa etapa, os serviços de assistência técnica ao produtor têm como objetivo aumentar a produtividade e o valor do produto (MURRAY; RAYNOLDS; TAYLOR, 2006). Nessa fase, os principais atores são os pequenos produtores e o Estado (em alguns países o Estado tem participação relevante na produção). 
(ii) produção: o café é cultivado em grandes ou pequenas propriedades, levando de 3 a 4 anos para se tornar produtivo. Quase $70 \%$ da oferta global de café é produzida em pequenas fazendas (BAMBER; GUINN; GEREFFI, 2014). Existem dois tipos de café cultivados para consumo: arábica e robusta. Considera-se que o primeiro produz um sabor superior, atingindo um preço relativo de mercado mais elevado. Além disso, suas plantas são mais produtivas. Mais uma vez, os principais atores nesse segmento da cadeia são os pequenos produtores e o Estado.

(iii) processamento: nesse estágio o café cereja é curado e moído. O primeiro processo pode ser seco ou úmido. Quando seco, expõe-se o café cereja ao sol durante um mês. Se úmido, ele é mergulhado na água. Este processo transmite melhor sabor para o café, resultando em preços relativos maiores. Em seguida, a moagem e lavagem são realizadas com vistas a remover camadas de pele ou casca. Tem-se, então, o grão de café verde (green coffee). Nessa fase, os pequenos produtores e o Estado são, ainda, importantes atores.

(iv) trade: mais de $80 \%$ dos grãos de café verde são transacionados internacionalmente (BAMBER; GUINN; GEREFFI, 2014). Logo, as companhias de trading têm um papel fundamental. Grandes torrefadores raramente compram grãos diretamente dos produtores. O segmento de trading é concentrado nos seis maiores comerciantes de café (Neumann, Ecom, Olam, etc.), que controlam cerca de metade do volume negociado internacionalmente (ITC, 2011; PONTE, 2002). O preço oficial do café é baseado na Bolsa de Mercadorias de Nova lorque (NYSE), sendo influenciado por diferentes fatores.

$\mathrm{Na}$ intermediação de cafés especiais, o papel dos traders ganha mais relevância, responsáveis por assegurar o atendimento aos padrões de produção requeridos. Esse nicho de mercado de cafés especiais cresceu consideravelmente. De acordo com a Associação de Cafés Especiais da América, cafés especiais, às vezes denominados 'gourmet' ou 'premium', são aqueles feitos de grãos excepcionais cultivados somente em condições climáticas ideais. Eles tendem a apresentar sabores próprios, que são determinados pelas características da região em que são produzidos (SCAA, 2009). Os cafés certificados são agrupados dentro da categoria de cafés especiais. Existem diferentes tipos de certificação, tais como de comércio justo, produção orgânica, certificação de origem, etc.

(v) torrefação: os torrefadores produzem grãos de café torrado e café instantâneo (solúvel). O mercado de torrefação inclui tanto grãos mistos quanto grãos específicos de diferentes traders. O grão robusta é mais utilizado para o café instantâneo. $O$ processo de descafeinação, quando realizado, é feito antes da torrefação. A torrefação geralmente se concentra nos principais mercados consumidores da Europa, da América do Norte e, crescentemente, do Leste Asiático. Esse segmento, assim como o de traders, é altamente concentrado, em particular o de café instantâneo, sendo dominado pela Kraft e Nestlé (ITC, 2011). Elas também podem controlar a comercialização de seus produtos, vendendo café torrado por meio de operações de varejo internas ou acordos de distribuição exclusiva com supermercados.

(vi) comercialização: o café é vendido principalmente no varejo, na indústria de serviços de alimentação e nas cafeterias especiais. O varejo corresponde a $70-80 \%$ do consumo de café, sendo os grandes supermercados os principais players 
(BAMBER; GUINN; GEREFFI, 2014). Recentemente, as cadeias de supermercado têm, também, torrado e comercializado suas próprias marcas de café. Já as cafeterias especiais se destacaram nos Estados Unidos, Europa e Leste Asiático nos anos 2000 (FEUERSTEIN, 2007). Essas cafeterias vendem tanto cafés prontos quanto grãos torrados, cujo o processo foi feito artesanalmente ou em pequena escala. A competição nesse mercado se dá com base na qualidade do café, a partir de certificados que, usualmente, destacam as condições em que ele foi produzido (GOLDING; PEATTIE, 2005; PONTE, 2002).

\section{Alcance geográfico: a geografia da demanda e oferta na CGV do café}

A geografia da demanda e oferta do café na CGV se dá da seguinte forma: de um lado, os principais exportadores de café verde são os países da América do Sul e do Sudeste Asiático, de outro, os países europeus, os Estados Unidos e o Canadá atuam como centro de distribuição do produto, assumindo, às vezes, o seu processo de torrefação.

Em termos de valor e quantidade, Brasil, Colômbia e Alemanha são os principais exportadores mundiais. Em termos de valor exportado, a Suíça aparece entre os cincos maiores exportadores, e, em termos de quantidade, Honduras completa o grupo (Gráfico 1).

Gráfico 1: Cinco principais países exportadores de café - 2017 - em \% do total global

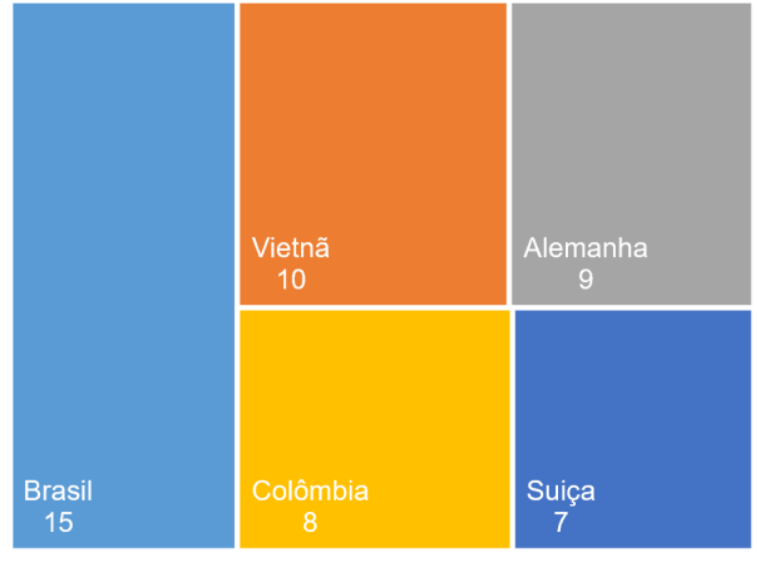

(a) Em termos de valor - US\$

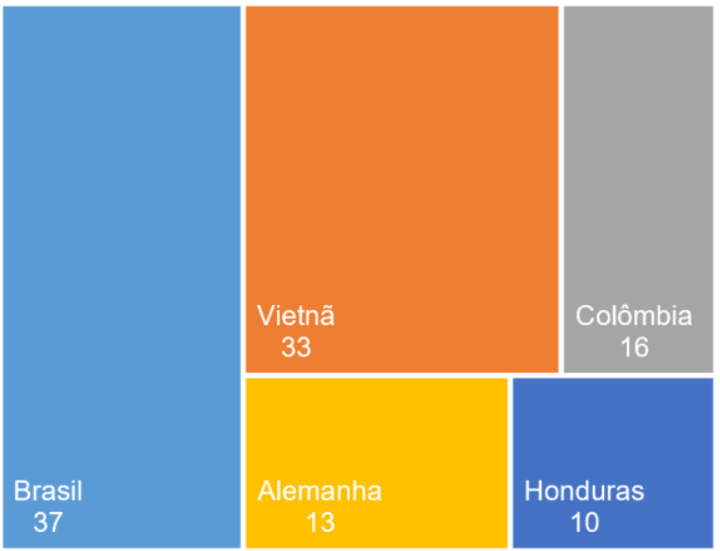

(b) Em termos de Quantidade - Kg líquido

Fonte: elaboração própria a partir de dados do Comtrade: HS 0901.

À exceção da Alemanha 6 , os demais países representados no Gráfico 1 b são também os principais produtores de café. De acordo com os dados da ICO, a produção brasileira ${ }^{7}$, tanto de café arábica quanto de robusta, é, de longe, a mais relevante. Em

\footnotetext{
${ }^{6}$ A Alemanha atua como importante distribuidora de café no mercado europeu.

${ }^{7}$ Com base no ano de colheita 2017-18, o Brasil produziu 51 mil sacas de café, e o Vietnã, segundo maior produtor, 29.500 sacas de café.
} 
seguida, aparece o Vietnã, cuja produção atual é majoritariamente de café robusta e a Colômbia, que é a maior produtora exclusiva de café arábica.

Destaca-se que em 2017, do total do valor exportado (Gráfico 1), a participação do Brasil foi de $15 \%$, e, do total da quantidade exportada, foi de $37 \%$. Ou seja, a participação de mercado em termos de quantidade é superior à participação em termos de valor. Essa diferença, tanto no caso brasileiro como no caso dos principais países produtores, denota a sua inserção nos segmentos inferiores da CGV, com baixo valor agregado.

Os principais produtores de café são, geralmente, especializados na exportação do café verde. Inclusive, em termos de quantidade, mais de $80 \%$ das exportações são de café não torrado e não descafeinado, que corresponde ao café verde (Tabela 1). Nesse estágio, ele conserva melhor as propriedades do café.

Tabela 1: Exportação mundial de café por tipo de produto - 2017 - em \% do total global

\begin{tabular}{l|l|l|l}
\hline Especificação & Código HS & Valor(US\$) - \% & Kg líquido - \% \\
\hline Café não torrado e não descafeinado & 90111 & 61,98 & 82,48 \\
Café não torrado descafeinado & 90112 & 2,65 & 3,07 \\
Café torrado e não descafeinado & 90121 & 33,42 & 13,88 \\
Café torrado e descafeinado & 90122 & 1,95 & 0,57
\end{tabular}

Fonte: elaboração própria a partir de dados do Comtrade: HS 090112, 90111, 90122, 90121.

Os principais exportadores de café torrado são países da Europa e da América do Norte (Gráfico 2). Nesses países, existem políticas comerciais que incentivam a torrefação do café. Na Alemanha, Suíça, Itália e em outros países foram eliminadas as tarifas de importação de grãos de café verde e, simultaneamente, estabelecidas tarifas de importação de café torrado e instantâneo, tipicamente ao redor de $9 \%$ (BAMBER; GUINN; GEREFFI, 2014). Nos Estados Unidos existem tarifas de importação para o café instantâneo, mas não para o café torrado. A Suíça, em particular, aumentou consideravelmente sua participação no mercado de café torrado e instantâneo em virtude da crescente demanda de países consumidores por café em dose única (incluindo as cápsulas de café). A Nestlé, cuja produção se concentra no país, tem liderado esse segmento.

Gráfico 2: Cinco principais países exportadores de café não torrado e torrado 2017 - em \% do total global

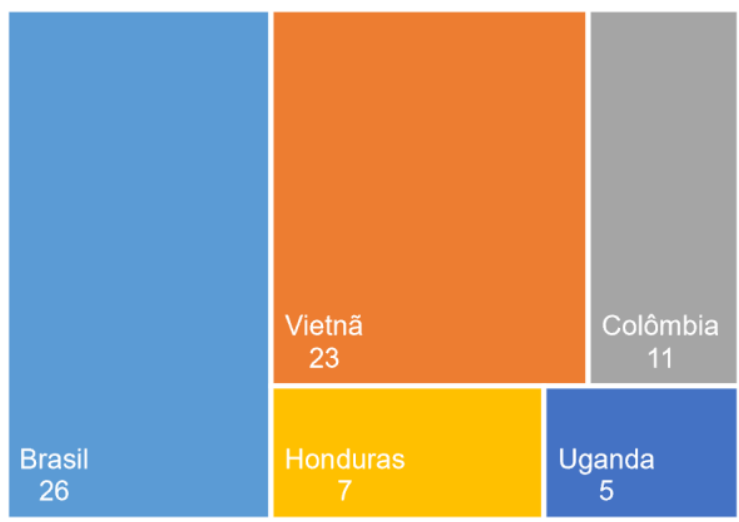

(a) Café não torrado
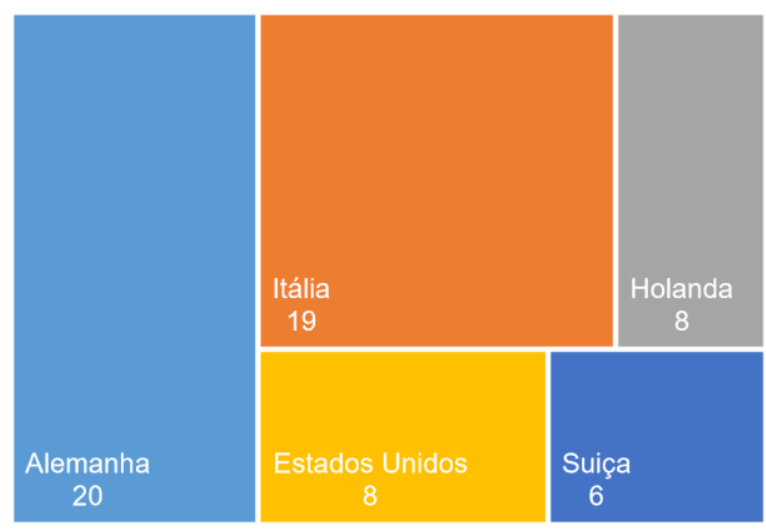

(b) Café torrado

Fonte: elaboração própria a partir de dados do Comtrade, HS 90111 e HS 90121. 
Além disso, ainda na década de 1990, o café torrado e moído tinha elevada perecibilidade. Assim, a indústria de torrefação se estabelecia perto dos mercados consumidores. No entanto, a partir da introdução da embalagem à vácuo, essa questão foi equacionada, de modo que, atualmente, o prazo de validade dos cafés torrados comercializados no varejo se aproxima de um ano. Em certa medida, essa questão explica, parcialmente, a razão pela qual as principais torrefadoras se localizam na Europa e nos Estados Unidos.

Não coincidentemente, os principais importadores de café não torrado são os países da América do Norte, da Europa e Japão. Além de serem um mercado consumidor importante, esses países participam dos segmentos superiores da CGV do café (principalmente nos segmentos de trade e torrefação). Alguns países europeus $^{8}$ se configuram como centros de reexportação de café, importando café verde e distribuindo-o pelo mercado europeu. A maior comerciante de café Neumann Gruppe - localiza-se na Alemanha, e o porto de Antuérpia, na Bélgica, é um importante centro de distribuição (PALHARES et al., 2015).

Recentemente, a demanda de café, mais estabilizada em mercados mais maduros como o europeu, tem sido impulsionada pelos mercados emergentes, especialmente o da China. As importações chinesas, em valor, mais do que triplicaram entre 2012 e 2016, e, em quantidade, cresceram quase 50\% no mesmo período. O crescimento no mercado de café especiais é também bastante forte na China, havendo um expressivo aumento da presença da franquia Starbucks (BURKITT, 2012).

\section{Governança}

Do ponto de vista teórico, as CGVs podem ser coordenadas pelo produtor (producer-driven), quando as corporações transnacionais controlam o conjunto de fornecedores e distribuidores que compõem o sistema de produção, ou pelos compradores (buyer-driven), quando grandes compradores internacionais coordenam a cadeia (GEREFFI, 1994). No entanto, esse modelo simplificado de análise, embora útil, está se tornando mais complexo e dinâmico na medida em que a estrutura de governança depende, cada vez mais, das diversas conexões entre as atividades da cadeia (GEREFFI; HUMPHREY; STURGEON, 2005).

No CGV do café as firmas líderes são as responsáveis pela torrefação. A Kraft, Nestlé, Sara Lee e Smuckers respondem por mais de $40 \%$ do mercado de grãos torrados, sendo que as duas primeiras, juntas, dominam o mercado de café instantâneo (participação superior a 70\%) (BAMBER; GUINN; GEREFFI, 2014). Em virtude dessa grande concentração, do uso de técnicas de gerenciamento de estoque e do controle sobre a marca do produto, elas têm grande poder de comando na cadeia, tanto upstream quanto downstream. Em geral, os grandes torrefadores não negociam com fornecedores que não conseguem garantir um mínimo de 60.000 toneladas/ano de café arábica (PONTE, 2002). Dessa forma, esse segmento do mercado exclui países em que a produção é de baixa escala e a oferta não é previsível.

As tradings companies também desempenham um papel importante no controle do acesso ao mercado de café commodity. Usualmente, elas buscam, rastreiam e gerenciam grandes ofertas de café verde para empresas torrefadoras (KAPLINSKY; FITTER, 2004). Nesse segmento, o mercado é também concentrado,

\footnotetext{
${ }^{8}$ Além da Alemanha e da Bélgica, os Estados Unidos também é um importante reexportador de café.
} 
sendo que as principais tradings controlam mais de $60 \%$ do comércio global de café (BAMBER; GUINN; GEREFFI, 2014). No entanto, as próprias empresas torrefadoras têm adotado regras mais rígidas para a gestão do estoque e, consequentemente, estabelecido relações diretas com os produtores de café (PONTE, 2002). Assim, 0 equilíbrio do poder na CGV do café tem migrado dos traders para os torrefadores.

Essa mudança na dinâmica de governança aumenta as oportunidades dos produtores se conectarem diretamente com os torrefadores no segmento de mercado do café commodity, beneficiando-se dessa interação tanto em questões da qualidade da produção, quanto dos preços auferidos. Entretanto, pequenos produtores de café têm baixo poder de barganha nesse mercado em virtude de economias de escala limitadas, dificuldade de comercialização e baixo acesso às informações e condições do mercado consumidor final. Adicionalmente, eles não têm o capital necessário para transportar o produto para o porto, dependendo, então, dos traders ou dos torrefadores.

No mercado de café especial, os torrefadores tendem a se envolver mais diretamente com produtores, a fim de assegurar a qualidade do café. No início dos anos 2000, grandes torrefadores de café especial como a Starbucks começaram a negociar diretamente com os produtores. Além disso, alguns traders começaram a se integrar verticalmente nas operações de produção e processamento (PONTE, 2002). Nesse arranjo, os produtores podem se beneficiar se houver compromisso dos traders e dos torrefadores em garantir preços mais altos e em manter uma relação duradoura com os fornecedores de café de alta qualidade.

No nicho de mercado certificado, a governança é também mais controlada do que no mercado de café tradicional. Geralmente envolve uma terceira parte responsável por certificar os produtores, prover assistência técnica e realizar o controle de qualidade. O certificado de fair trade, no qual uma agência busca assegurar que o preço recebido pelo produtor seja justo, é um dos mais conhecidos. No entanto, ainda não é consensual que esquemas de certificação resultem em melhores vendas para os pequenos produtores (BARHAM; WEBER, 2012; MÉNDEZ et al., 2010; RUBEN; FORT, 2012; VALKILA; NYGREN, 2010).

\section{A PRODUÇÃO DE CAFÉ EM MINAS GERAIS E NO BRASIL: contexto institucional}

Em Minas Gerais e no Brasil a participação do setor agropecuário no PIB, nos últimos dez anos, está estabilizada em torno de 5\%. No entanto, o percentual de pessoas ocupadas no setor vem caindo gradativamente. No último trimestre de 2018 correspondeu a aproximadamente $9 \%$ do total de ocupados (FJP, 2019; IBGEa, 2019).

Na produção de café, especificamente, o Brasil se destaca como maior produtor mundial. São quase 2 milhões de hectares plantados e uma produção, em 2018, superior a 3,5 milhões de toneladas. Cerca de $70 \%$ da produção é de café arábica e os outros $30 \%$ de robusta. O estado de Minas Gerais, sozinho, responde por mais de $50 \%$ da produção, sendo praticamente toda a produção de café arábica (IBGEb, 2019).

Além de maior produtor de café arábica e robusta, o Brasil é também o maior exportador de café verde. A participação de Minas Gerais é superior a $75 \%$ das exportações em termos de valor e quantidade. Em seguida, aparecem os estados do Espírito Santo e São Paulo (Gráfico 3). 
Gráfico 3 - Participação dos principais estados exportadores de café - Brasil - 2018 - em \% do total nacional

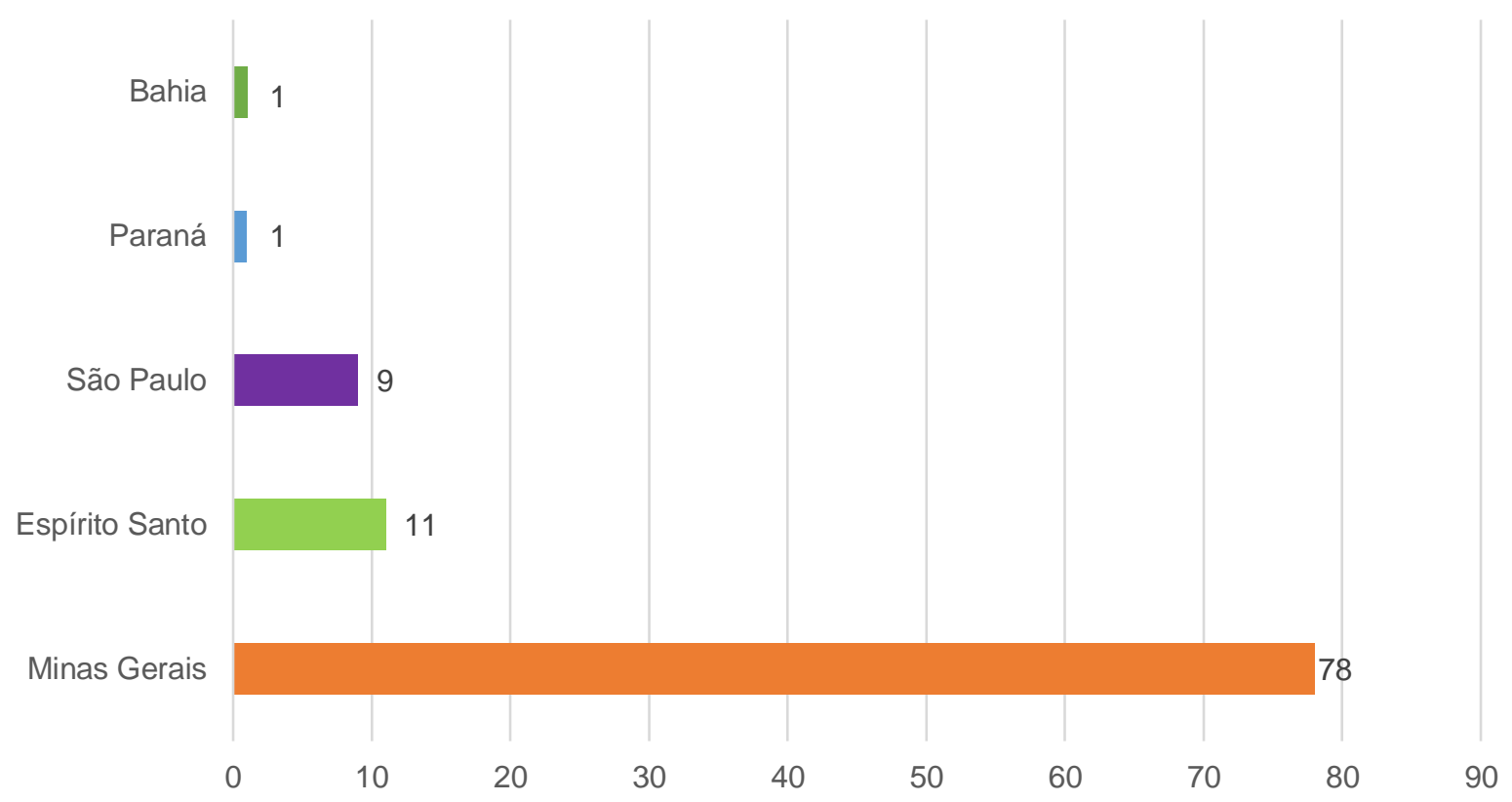

Fonte: elaboração própria a partir de dados do Ministério da Indústria, Comércio Exterior e Serviços (MDIC) com base nas classificações HS 090112, 90111, 90122, 90121, 090190.

As exportações brasileiras (e mineiras) se concentram na venda de café não torrado e não descafeinado para Estados Unidos e Alemanha. Em Minas Gerais o café é um dos itens mais importantes da pauta de exportação, representando cerca de $10 \%$ do valor total exportado. Em 2018, foram mais de 3 bilhões de dólares.

Embora seja o principal produtor e exportador mundial, o Brasil ainda importa café torrado predominantemente da Suíça. Em 2018, foram importados quase US\$ 60 milhões, que equivalem a cerca de $2 \%$ do valor exportado de café verde. São Paulo é o principal importador, em termos de valor e quantidade, pois boa parte do produto entra no mercado brasileiro a partir do porto de Santos.

A produção de café brasileira é realizada majoritariamente por pequenos e médios produtores, que geralmente estão associados a uma cooperativa, sindicato ou associação de classe. No entanto, o estudo de PALHARES et al. (2015) aponta que o nível de associativismo ainda é baixo, respondendo por apenas $30 \%$ da produção brasileira.

O segmento de torrefação e moagem é formado por aproximadamente 20.000 empresas. A maior indústria de café no Brasil pertence ao Grupo Três Corações. Em seguida, aparece a holandesa Jacobs Douwe Egberts (JDE), que é uma das principais empresas no setor (ABIC, 2019). Nesse segmento, assim como acontece em escala mundial, existe uma forte concentração de mercado. Poucas empresas são responsáveis quase pela totalidade do processamento do café e a competição entre elas se dá via preço. Embora Minas Gerais seja o principal produtor, o processamento do café é feito majoritariamente em São Paulo (PALHARES et al., 2015).

No varejo, onde a maior parte do café produzido é comercializada, os grupos que se destacam no Brasil são o Carrefour, Pão de Açúcar e Walmart (IBVAR, 2019). Em relação a redes de cafeterias, existem unidades da rede Starbucks no eixo RioSão Paulo.

O Estado, em nível federal e estadual, é também um ator importante da cadeia produtiva do café. Ele atua, sobretudo, na parte de crédito, fomento à pesquisa e 
inovação, e assistência e extensão rural. Na parte de crédito, o Programa de Fortalecimento da Agricultura Familiar (Pronaf) é responsável por financiar projetos individuais ou coletivos que gerem renda aos agricultores familiares ou assentados. Existem diversas linhas de crédito, inclusive para o investimento em infraestrutura cujo objetivo seja o beneficiamento, o processamento e a comercialização da produção.

O Fundo de Defesa da Economia Cafeeira (Funcafé) também disponibiliza linhas de crédito. Seu objetivo é apoiar o desenvolvimento cafeeiro com investimentos em pesquisas, capacitação e ações promocionais. Em 2015, foram gastos quase 3 bilhões nesses itens. O CDPC é quem aprova os gastos do fundo. Fazem parte do conselho representantes do governo e das associações de café (agricultura, indústria, exportação, etc.) (MAPA, 2015). Em Minas Gerais, quem operacionaliza as linhas de crédito do Funcafé é o Banco de Desenvolvimento de Minas Gerais (BDMG).

Em termos de pesquisa, a Empresa Brasileira de Pesquisa Agropecuária (Embrapa) e, mais especificamente, a Embrapa Café, é responsável por coordenar a sua execução e viabilizar soluções tecnológicas inovadoras para o desenvolvimento do agronegócio do café brasileiro. O programa de pesquisa é realizado pelo Consórcio Brasileiro de Pesquisa e Desenvolvimento do Café (Consórcio Pesquisa Café), composto por mais de 30 instituições. Em sua maioria, são instituições de pesquisa estaduais (similares à Empresa de Pesquisa Agropecuária de Minas Gerais - Epamig) e universidades federais.

Em nível estadual, as empresas (ou institutos) de assistência técnica e extensão rural são muito importantes no processo de desenvolvimento dos pequenos produtores. Especificamente, a Empresa de Assistência Técnica e Rural de Minas Gerais (Emater-MG) é a maior empresa pública do setor no Brasil.

A cadeia de valor do café de Minas Gerais compõe a agenda estratégica da Emater. Dentre as ações promovidas, destacam-se o concurso de qualidade dos cafés de Minas Gerais, a promoção do Circuito Mineiro da Cafeicultura (eventos de difusão de tecnologia) e o Programa Certifica Minas (certificação de boas práticas de produção) (EMATER-MG, 2015).

Em suma, observa-se que existem no setor cafeeiro brasileiro vários atores relevantes ao longo da cadeia. Muitos deles se encontram associados a alguma entidade representativa: Associação Brasileira da Indústria de Café - ABIC, Associação Brasileira da Indústria de Café Solúvel - ABICS, Conselho dos Exportadores de Café do Brasil - Cecafé, Confederação da Agricultura e Pecuária do Brasil - CNA, associações e cooperativas de cafeicultores, sindicatos da indústria do café, etc. Todos esses atores exercem influência na cadeia produtiva do café brasileiro.

\section{ANÁLISE DA CGV DO CAFÉ: alternativas para Minas Gerais}

A partir da caracterização da CGV do café, observa-se que países em desenvolvimento participam das etapas iniciais dessa cadeia de valor e países desenvolvidos estão, principalmente, nos últimos estágios. De acordo com os dados da ICO, em 2016, o preço do café verde pago ao produtor foi, em média, equivalente a US\$1.04/kg; já o preço do café torrado no varejo foi, em média, US\$5,85/kg. Logo, entre essas duas etapas, foram adicionados cerca de US $\$ 5,00$ ao preço do produto. Assim, à medida que se avança na CGV do café, o valor adicionado cresce consideravelmente, conforme ilustrado na Figura 1. 
Figura 1: Decomposição do preço do café ao consumidor na União Europeia

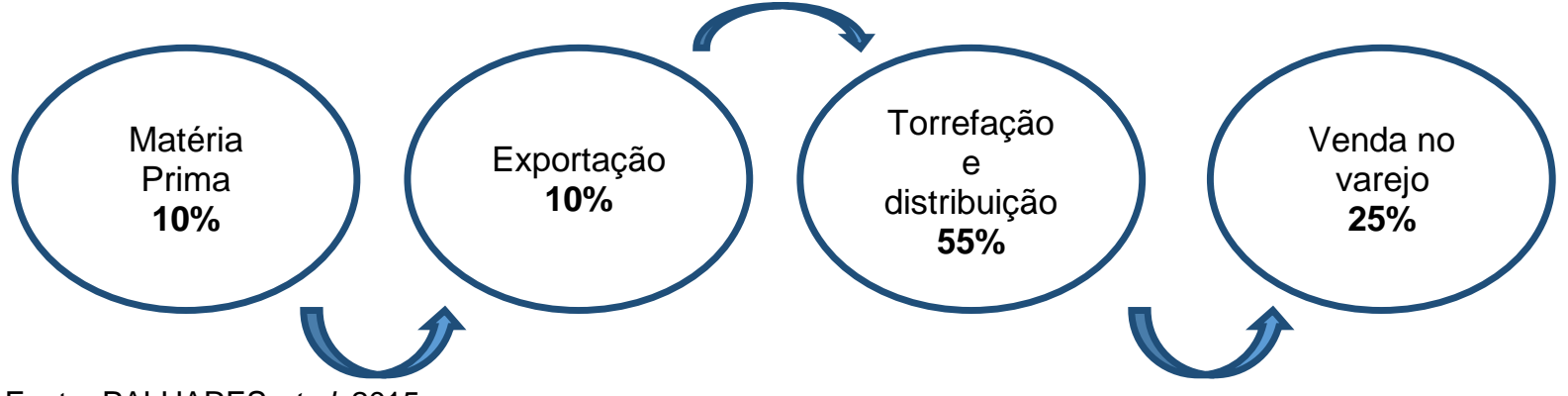

Fonte: PALHARES et al, 2015.

O preço pago ao produtor, cotado na Bolsa de Nova lorque, é bastante volátil (IMF, 2020). As oscilações se devem tanto a fatores relacionados à oferta (e.g., secas no Brasil e na Colômbia), quanto à demanda. Considerando que o preço é cotado em dólares, as oscilações da taxa de câmbio também afetam a competitividade e a rentabilidade dos produtores.

Em termos de governança, a cadeia produtiva é comandada pelos torrefadores. Entre os produtores e os torrefadores, de acordo com a estrutura de insumos e produtos, há ainda a presença das tradings, ou seja, os produtores têm baixa influência sobre o principal segmento da cadeia (torrefadores).

Nesse contexto, os produtores de café commodity, além de não participarem das fases mais avançadas da CGV, têm suas receitas vinculadas, fortemente, a fatores exógenos, tais quais a variação do câmbio e eventos naturais. Logo, esse modelo de inserção não é o preferível, pois além de se sujeitar a variáveis não controláveis, apropria-se de menor parte do valor adicionado na cadeia.

Nesse cenário, a emergência dos cafés especiais nas últimas décadas abre uma oportunidade para os produtores de café. De um lado, as traders podem assumir o papel de garantir a qualidade e procedência do café; de outro, os torrefadores podem optar por se aproximarem dos produtores, estabelecendo uma conexão direta. Em qualquer hipótese, a forma e as condições de produção ganham relevância na cadeia produtiva do café. Logo, os países produtores de café podem se beneficiar, assumindo um papel mais relevante na cadeia produtiva.

$\mathrm{Na}$ literatura da CGV, upgrading corresponde a assumir atividades de maior valor agregado. $\mathrm{O}$ upgrading funcional, isto é, incorporar funções adicionais na cadeia de valor (e.g., atividades de gestão da marca) é, usualmente, o objetivo. No entanto, existem grandes barreiras de entrada nos estágios de maior valor agregado da CGV. Geralmente, nessas etapas, o mercado é muito concentrado. O Quadro 2 sumariza as principais estratégias de upgrading na CGV. 


\section{Quadro 2: Estratégia de upgrade na cadeia global do café}

\begin{tabular}{|c|c|c|c|}
\hline & Etapas & nvolvidas & Descrição \\
\hline \multirow{4}{*}{ 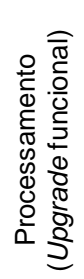 } & Produção & Processamento & \multirow{3}{*}{$\begin{array}{l}\text { O processamento, incluindo os processos seco, úmido e a moagem, tem de ser } \\
\text { realizado imediatamente após a colheita, de modo que essas atividades têm } \\
\text { que estar perto dos centros de produção. A qualidade do processamento afeta o } \\
\text { preço que os compradores pagam pelo café. }\end{array}$} \\
\hline & arábica & processo úmido & \\
\hline & robusta & processo seco & \\
\hline & & Moagem & $\begin{array}{l}\text { Exemplo: em 1972, a Etiópia substituiu o processo de secagem a sol pelas } \\
\text { estações de lavagem. Hoje, o café da Etiópia é considerado um dos melhores } \\
\text { do mundo. }\end{array}$ \\
\hline \multirow{4}{*}{ 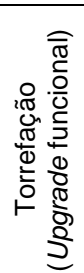 } & Processamento & Torrefação & \multirow{3}{*}{$\begin{array}{l}\text { A torrefação tende a ser feita perto do mercado consumidor, limitando seu } \\
\text { potencial à demanda do mercado consumidor. }\end{array}$} \\
\hline & processo úmido & descafeinação & \\
\hline & processo seco & café torrado & \\
\hline & moagem & café solúvel & $\begin{array}{l}\text { Exemplo: Costa Rica iniciou a torrefação de café nos anos } 1980 \text { para atender o } \\
\text { mercado local e de turistas. Hoje, são mais de } 27 \text { pequenas e médias empresas } \\
\text { de torrefação. }\end{array}$ \\
\hline \multirow{4}{*}{ 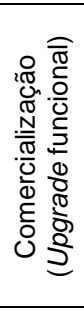 } & Torrefação & Comercialização & \multirow{3}{*}{$\begin{array}{l}\text { A comercialização cria identidade da marca de acordo om a qualidade e as } \\
\text { características de sabor. Iniciativas efetivas de comercialização envolvem a } \\
\text { promoção da singularidade do café. }\end{array}$} \\
\hline & descafeinação & supermercados & \\
\hline & café torrado & $\begin{array}{l}\text { serviços de } \\
\text { comida }\end{array}$ & \\
\hline & café solúvel & Cafeterias & $\begin{array}{l}\text { Exemplo: nos anos } 2000 \text {, Ruanda instituiu um programa para aumentar os } \\
\text { ganhos e reposicionar sua marca de café. As iniciativas envolveram, além da } \\
\text { melhora da produção e do processamento, iniciativas de marketing. A Colômbia } \\
\text { também é um país que investiu bastante no marketing de seu produto. }\end{array}$ \\
\hline \multirow{3}{*}{$\begin{array}{l}0 \\
\frac{0}{3} \\
0 \\
0 \\
0 \\
0 \\
0 \\
0 \\
0 \\
0 \\
0 \\
0 \\
5\end{array}$} & \multirow{3}{*}{\multicolumn{2}{|c|}{$\begin{array}{l}\text { Envolve todas as etapas e todos os } \\
\text { segmentos da CGV }\end{array}$}} & $\begin{array}{l}\text { Envolve a produção de produtos de maior valor agregado. } \\
\text { Requer conhecimento das preferências do mercado, dos custos e dos preços. } \\
\text { Nichos de mercado certificado e especial são exemplos de upgrade de produto } \\
\text { que requerem uprade do processo primeiro. }\end{array}$ \\
\hline & & & \\
\hline & & & $\begin{array}{l}\text { Exemplo: iniciativas recentes do governo do Vietnã têm buscado dobrar o } \\
\text { cultivo do café arábica e também estimulado a substituição de plantações } \\
\text { antigas de robusta por arábica. }\end{array}$ \\
\hline \multirow{2}{*}{ 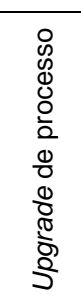 } & \multirow{2}{*}{\multicolumn{2}{|c|}{$\begin{array}{l}\text { Envolve todas as etapas e todos os } \\
\text { segmentos da CGV }\end{array}$}} & $\begin{array}{l}\text { Introdução de novas tecnologias no sistema produtivo e restruturação do } \\
\text { sistema existente para aumentar a eficiência. } \\
\text { Exemplos: café plantado na sombra, produção orgânica de café, } \\
\text { aperfeiçoamento das técnicas de colheita, etc. }\end{array}$ \\
\hline & & & $\begin{array}{l}\text { Exemplo: em 2003, a associação de produtores da Guatemala lançou um } \\
\text { sistema de rastreamento da produção para identificar as características e a } \\
\text { localização de todo café plantado na região da Antígua. }\end{array}$ \\
\hline \multirow{2}{*}{ 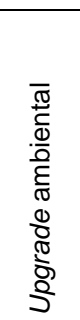 } & \multirow{2}{*}{\multicolumn{2}{|c|}{$\begin{array}{l}\text { Envolve as etapas de insumos, } \\
\text { produção e processamento da CGV }\end{array}$}} & $\begin{array}{l}\text { Envolve a adoção de práticas menos nocivas ao meio ambiente. } \\
\text { Geralmente são uma pré-condição para exportação de cafés certificados }\end{array}$ \\
\hline & & & $\begin{array}{l}\text { Exemplo: a poluição da água era um fator central nas plantações de café na } \\
\text { América Central. Nos anos } 2000 \text {, foram adotadas iniciativas para diminuir a } \\
\text { poluições decorrente do processo do tipo úmido (instalação de máquinas } \\
\text { ecológicas e treinamento). }\end{array}$ \\
\hline
\end{tabular}

Fonte: Adaptado de Bamber, Guinn e Gereffi (2014).

No caso brasileiro, em particular de Minas Gerais, entende-se que há dois caminhos prioritários para o avanço na CGV. O primeiro, no qual já existem iniciativas, seria ampliar sua participação na comercialização de cafés especiais; o segundo seria entrar no mercado de exportação de grão torrado. Inclusive, pode-se combinar ambos, exportando café especial torrado. 


\section{Upgrade de produto}

No caso do mercado de café, o upgrade de produto envolve a produção de cafés com nível de qualidade superior ou cujo processo de produção priorize a sustentabilidade, denominados cafés especiais. Usualmente, eles são certificados por uma terceira parte, com vistas a garantir o atendimento de quesitos de qualidade $e$ sustentabilidade. $O$ consumo de cafés especiais tem crescido consideravelmente em todos os países.

De modo geral, os estudos apontam as seguintes vantagens da certificação: preços mais altos, maior qualificação da mão-de-obra e melhores conexões com a rede de produção internacional. Dentre as desvantagens, elencam-se: alto custo de certificação, necessidade de investimentos em mão-de-obra e o fato de a compra e o pagamento desse tipo de café ocorrer mais no final do período de colheita (MENDEZ et al., 2010).

Alguns países, como a Costa Rica e a Etiópia, estabeleceram um modelo de produção voltado para esse nicho de mercado. Na Costa Rica, por exemplo, $80 \%$ da produção de café é para o mercado de cafés especiais. Os maiores produtores nesse nicho de mercado são a Colômbia e a Guatemala (BAMBER; GUINN; GEREFFI, 2014).

Em países em que predomina a produção de baixa escala e onde existam características ambientais adequadas, o que é compatível com o caso brasileiro, o upgrade de produto orientado pela qualidade e sustentabilidade é uma alternativa relevante. Nesse segmento, os torrefadores tendem a se aproximar dos produtores, 0 que pode beneficiar os produtores, aumentando o preço pago.

No Brasil, segundo Saes e Spers (2006), as principais estratégias de diferenciação utilizadas pelos produtores de café são a identificação de origem, certificados de qualidade, de café orgânico, de comércio justo e/ou boas práticas agrícolas. Segundo a Associação Brasileira de Cafés Especiais (BSA), a produção de cafés especiais evoluiu, em média, $15 \%$ nos últimos anos, saltando de 5,2 milhões de sacas, em 2015, para cerca de 8,5 milhões, em 2017. Minas Gerais, em especial o Sul de Minas, é uma das regiões mais premiadas pela qualidade do café.

A Emater-MG possui um programa de certificação de propriedades cafeeiras. Seu objetivo é promover a adequação dessas propriedades às boas práticas de produção. De acordo com a avaliação de Amaral et al. (2017), o programa Certifica Minas Café da Emater-MG tem tido bons resultados, auxiliando os pequenos produtores a aumentar sua produção de café especial e, consequentemente, sua lucratividade.

Portanto, tendo em vista que o preço médio do café mineiro e brasileiro exportado não está entre os maiores, deve-se incentivar a produção de cafés especiais. Em parte, em Minas Gerais, isso já é feito através do trabalho desenvolvido pela Emater, Epamig e algumas universidades federais.

\section{Upgrade funcional - torrefação}

Atualmente a indústria de café torrado e moído no Brasil está voltada para o mercado interno. O Brasil é o segundo maior mercado consumidor de café, atrás apenas do Estados Unidos. Em termos per capita, todavia, os países da União Europeia são os principais consumidores (ICO, 2019). Os grupos 3Corações, JDE e Mellita, juntos, são responsáveis por mais de 50\% do café torrado e moído (CCCMG, 2017). 
Nesse cenário, as pequenas torrefadoras têm buscado espaço através da comercialização do café com sua própria marca ou com a do varejista. Em escala microrregional, a barreira à entrada no setor de torrefação é baixa (estima-se que com 40 mil reais seja possível entrar no mercado), dificultando sua consolidação. Em Minas Gerais, o setor é mais pulverizado que a média nacional. São 375 indústrias que processam café em 183 municípios. Em sua maioria, são microempresas, que competem com base no preço, havendo pouca diferenciação de produto (PALHARES et al., 2015).

Essas microempresas têm dificuldade de cumprir a legislação em relação à rotulagem (SILVA; DUTRA, 2011). Geralmente trabalham com pouco estoque, o que dificulta o desenvolvimento de um blend característico que possa resultar em vantagem competitiva. A gestão interna carece de profissionalização, sendo, muitas das vezes, empresas familiares (PALHARES et al., 2015).

Em geral, do universo de quase 20.0000 empresas, apenas cerca de 5.000 são associadas à $A B I C$ e se submetem ao controle de padrão de pureza (ABIC, 2019). Boa parte delas ainda não são capazes de competir de forma rentável no mercado interno. Então, o primeiro desafio é aumentar a competitividade da maioria de micro e pequenas empresas torrefadoras. Assim, elas poderão atuar, primeiro, no mercado interno e, depois, no mercado externo.

No mercado internacional, a indústria torrefadora é também altamente concentrada, o que representa uma barreira à inserção das torrefadoras brasileiras. Inclusive, entre as cinco maiores torrefadoras que operam no Brasil, três são estrangeiras e outra é uma joint-venture entre o grupo 3 corações e a israelense Strauss (ABIC, 2019; CCCMG, 2017).

Adicionalmente, a participação do café torrado no comércio internacional, particularmente fora dos blocos econômicos ${ }^{9}$ é relativamente mais baixa (quando comparado ao café verde). Dentre os motivos, destaca-se a força das grandes torrefadoras, que têm grande poder de barganha com os países produtores. Essas poucas empresas (Nestlé, Modelez, DE Master Blends, etc.) vendem seus produtos e promovem suas marcas em larga escala.

Outro desafio são as barreiras impostas pelos países industrializados. $\mathrm{Na}$ Europa as tarifas ${ }^{10}$ à importação de café aumentam à medida que aumenta o grau de processamento do produto. Além da tarifa comum, cada país também cobra impostos específicos sobre o café. Há ainda uma legislação ampla e abrangente que regula e protege o mercado de produtos de origem agrícola. No Japão, as tarifas para qualquer tipo de café processado também são altas. Já no mercado americano, o que dificulta o acesso são as diversas barreiras não tarifárias, tais como a legislação antiterrorismo e antibiopirataria.

Um terceiro gargalo se relaciona à forma de apresentação do café. Geralmente, são feitos blends de café de diversas origens. Para a maior torrefadora italiana, a Illy, seu diferencial é justamente a combinação de café de diversas origens. A condição para a empresa abrir uma torrefadora no Brasil seria a possibilidade de importar café verde. No entanto, sua importação é dificultada pelos produtores brasileiros, apesar do setor ser extremamente competitivo (e na contramão do que fazem os países exportadores de café industrializado, que não estabelecem tarifas à importação de café verde).

\footnotetext{
${ }^{9}$ No caso brasileiro, mesmo no Mercado Comum do Sul (Mercosul), as exportações de café torrado são modestas. Em termos de valor, apenas 1\% das importações argentinas foram de café torrado brasileiro.

${ }^{10}$ Existe um sistema geral de preferências em que alguns países em desenvolvimento pagam tarifas menores. É o caso do Equador e da Colômbia, mas não o do Brasil.
} 
Por último, a venda de cápsulas de café tem crescido rapidamente. Nesse nicho, a estratégia das empresas é fidelizar a compra de seus produtos atrelando-os à utilização de máquinas de café compatíveis apenas com sua marca. Nesse caso, seria necessário que os torrefadores brasileiros, de pequeno e médio porte, buscassem um fabricante de máquinas que se dispusesse a licenciar seus produtos, ou, então, que eles terceirizassem a produção de cápsulas com algumas fabricantes que se instalaram recentemente no Brasil (PALHARES et al., 2015). As cápsulas de café poderiam ser comercializadas tanto no mercado externo quanto no mercado interno.

De modo geral, a inserção do setor cafeeiro brasileiro, nas exportações de café torrado, além de aumentar a participação das empresas no valor adicionado, proporcionaria ganhos de escala, diminuição da sazonalidade das vendas e da ociosidade dos equipamentos, maior capacitação tecnológica em processos e produtos e melhoria da gestão da empresa. Adicionalmente, seriam gerados novos empregos. De acordo com Vegro et al. (2005), o aumento de 10 mil sacas de produção gera 9 empregos nas torrefadoras, 8 nos demais segmentos e mais 70 pelo efeito renda em outros setores.

Em linhas gerais, o upgrade funcional para a torrefação, segmento que mais agrega valor na CGV do café, tem barreiras internas e externas. Do ponto de vista interno, destacam-se: (i) a baixa profissionalização das pequenas torrefadoras contribui para sua baixa competitividade, inviabilizando sua inserção no mercado externo; (ii) a ausência de ações para a promoção do café brasileiro; (iii) a falta de recursos público para o setor industrial; e (iv) a dificuldade de importação de café verde. Do ponto de vista externo, realçam-se: (i) a alta concentração do mercado; (ii) a existência de diversas barreiras tarifárias e não tarifárias; e (iii) a falta de interesse de empresas estrangeiras instaladas no Brasil em exportar café torrado e moído para competir com suas filiais instaladas em outros países (PALHARES et al., 2015).

No caso da indústria cafeeira mineira, em particular, sua participação na produção é bastante inferior à de São Paulo, embora o estado seja o principal produtor de café verde. A excessiva fragmentação do setor, aliada à baixa profissionalização, são fatores que demandam políticas capazes de reverter esse quadro. Do ponto de vista institucional, as principais políticas públicas de Minas Gerais estão voltadas para o setor agropecuário, através da Emater e Epamig. Cabe, então, ao governo mineiro desenhar políticas específicas para o setor industrial, capazes de superar os gargalos mencionados.

\section{CONSIDERAÇÕES FINAIS}

O retrato da CGV do café evidencia as seguintes características: na estrutura de insumos e produtos, as companhias de trading têm papel fundamental, ligando os grandes torrefadores aos produtores de café em grão; na geografia da oferta e demanda, os principais exportadores de café em grão são os países da América do Sul e da Ásia, e os principais exportadores de café torrado são países da Europa e da América do Norte; e na governança, as firmas líderes são as responsáveis pela torrefação. O contexto institucional da produção de café no Brasil mostra que o país é o principal produtor de café em grão, sendo que Minas Gerais concentra mais de $50 \%$ da produção do café arábica. O segmento da torrefação é bastante concentrado, embora exista um número grande de pequenas torrefadoras. Adicionalmente, instituições públicas oferecem linhas de crédito, desenvolvem pesquisas e prestam assistência técnica ao setor. 
A análise da participação de Minas Gerais e do Brasil na atual configuração da CGV revela que sua participação se dá apenas nos seus elos inferiores. Em escala regional, o caso de Minas Gerais é emblemático. Se o Brasil é o principal produtor mundial de café, o estado, sozinho, está entre os maiores produtores mundiais de café arábica. No entanto, quem processa a maior parte do café é o estado de São Paulo, sendo que a maior parte é para atender ao próprio mercado consumidor interno.

Esse padrão de inserção não é desejável, em primeiro lugar, porque o valor adicionado é bastante inferior; em segundo lugar, porque o preço das commodities é muito mais volátil; e, por último, porque não estimula a participação do setor industrial, que é o mais dinâmico da economia e tido como propulsor do desenvolvimento econômico. Portanto, é importante desenhar políticas públicas para o upgrade da produção de café em Minas Gerais, em especial o aumento da produção de cafés especiais e sua industrialização.

Em Minas Gerais, a EMATER e a EPAMIG são importantes agentes de apoio à produção de cafés especiais, inclusive com programas voltados para a sua certificação e melhoria de processos. No entanto, na fase de industrialização, não existem agências governamentais que cumpram esse papel.

A indústria cafeeira é composta, em sua maioria, por pequenas torrefadoras, com baixa profissionalização e pouco competitivas. Desse modo, não conseguem se inserir no mercado global. Nesse cenário, é importante desenhar políticas para o setor, tais como rever as barreiras impostas sobre a importação de café verde; direcionar parte dos recursos do Funcafé para o setor; e promover o produto brasileiro internacionalmente.

\section{REFERÊNCIAS}

ABIC (ASSOCIAÇÃO BRASILEIRA DA INDÚSTRIA DE CAFÉ. Indicadores da Indústria de Café / 2018. Disponível em: <http://abic.com.br/estatisticas/indicadoresda-industria/indicadores-da-industria-de-cafe-2018/>. Acesso em: 12 dez. 2019.

AMARAL, Ana Maria Santana et al. A Influência Do Certifica Minas Café Nas Lavouras Cafeeiras de Alfenas de Minas Gerais. Coffe Science, v. 12, n. 1, p. 114-123, 2017. Disponível em: <http://www.sbicafe.ufv.br/bitstream/handle/123456789/8268/Coffee\%20Science_v1 2_n1_p114-123_2017.pdf?sequence=1\&isAllowed=y>. Acesso em: 9 dez. 2019.

BAMBER, Penny; GUINN, Andrew; GEREFFI, Gary. Burundi in the Coffee Global Value Chain.. [S.I.]: Duke University: Center on Globalization, Governance and Competitiveness, 2014.

BARHAM, Bradford L.; WEBER, Jeremy G. The Economic Sustainability of Certified Coffee: Recent Evidence from Mexico and Peru. World Development, v. 40, n. 6, p. 1269-1279, 1 jun. 2012.2 Disponível em: <http://www.sciencedirect.com/science/article/pii/S0305750X11002890>. Acesso em: 9 dez. 2019.

CCCMG(CENTRO DO COMÉRCIO DE CAFÉ DO ESTADO DE MINAS GERAIS). Relatório internacional de tendências do café., no 9. UFLA: Centro de Inteligência em Mercado: UFLA: Centro de Inteligência em Mercado, 2017. Disponível em: $<\mathrm{http}$ ://cccmg.com.br/bureau-de-inteligencia-competitiva-do-cafe-divulga-relatoriointernacional-de-tendencias-do-cafe-v6-n9/>. Acesso em: 10 dez. 2019. 
FEUERSTEIN, Switgard. The Coffee Paradox: Global Markets, Commodity Trade and the Elusive Promise of Development. The World Economy, v. 30, n. 6, p. 1031-1032, 2007. Disponível em: <https://onlinelibrary.wiley.com/doi/abs/10.1111/j.14679701.2007.01041_3.x>. Acesso em: 9 dez. 2019.

FJP (FUNDAÇÃO JOÃO PINHEIRO). Produto Interno Bruto de Minas Gerais (PIB). Disponível em: <http://fjp.mg.gov.br/index.php/produtos-e-servicos1/2745-produtointerno-bruto-de-minas-gerais-pib-2>. Acesso em: 11 dez. 2019.

FURTADO, Celso. Formação econômica do Brasil. Tradução. Edição: 1 ed. São Paulo: Companhia das Letras, 2007.

GEREFFI, Gary; FERNANDEZ-STARK, Karina. Global Value Chain Analysis: A Primer (2nd Edition) / Global Value Chains.. [S.I.]: Duke University: Global Value Chains (GVC) Center, 2016. Disponível em: $<$ https://globalvaluechains.org/publication/global-value-chain-analysis-primer-2ndedition>. Acesso em: 9 dez. 2019.

GEREFFI, Gary; HUMPHREY, John; STURGEON, Timothy. The governance of global value chains. Review of International Political Economy, v. 12, n. 1, p. 78-104, fev. 2005Tradução.. Disponível em: <http://www.tandfonline.com/doi/abs/10.1080/09692290500049805>. Acesso em: 9 dez. 2019.

GOLDING, Kirsty; PEATTIE, Ken. In search of a golden blend: Perspectives on the marketing of fair trade coffee. Sustainable Development, v. 13, n. 3, p. 154-165, 2005. Disponível em: <https://ideas.repec.org/a/wly/sustdv/v13y2005i3p154-165.html>. Acesso em: 9 dez. 2019.

HUMPHREY, John; SCHMITZ, Hubert. How Does Insertion in Global Value Chains Affect Upgrading in Industrial Clusters? Regional Studies, v. 36, n. 9, p. 1017-1027, 1 dez. 2002. Disponível em: <https://doi.org/10.1080/0034340022000022198>. Acesso em: 9 dez. 2019.

IBGEa(Instituto Brasileiro de Geografia e Estatística). Tabela 6323: Pessoas de 14 Anos Ou Mais de Idade, Ocupadas Na Semana de Referência - Total, Coeficiente de Variação, Variações Percentuais e Absolutas Em Relação Aos Três Trimestres Móveis Anteriores e Ao Mesmo Trimestre Móvel Do Ano Anterior, e Média Anual - Por Grupamentos de Atividade No Trabalho Principal. Disponível em: <https://sidra.ibge.gov.br/tabela/6323\#resultado>. Acesso em: 11 dez. 2019.

IBGEb(Instituto Brasileiro de Geografia e Estatística). Tabela 5457: Área Plantada Ou Destinada à Colheita, Área Colhida, Quantidade Produzida, Rendimento Médio e Valor Da Produção Das Lavouras Temporárias e Permanentes. Disponível em: <https://sidra.ibge.gov.br/tabela/5457\#resultado>. Acesso em: 12 dez. 2019.

IBEVAR (Instituto Brasileiro de Executivos de Varejo e Mercado de Consumo). Ranking IBEVAR. 120 Maiores empresas do varejo brasileiro. São Paulo, 2019. 
ICO (INTERNATIONAL COFFE ORGANIZATION). Historical Data on the Global Coffee Trade. Disponível em: <http://www.ico.org/new_historical.asp?section=Statistics>. Acesso em: 10 dez. 2019.

INTERNATIONAL TRADE CENTER (ITC). The Coffee Exporter's Guide. Tradução. 3. ed. Suiça: Gênova, 2011.

KAPLINSKY, Raphael; FITTER, Robert. Technology and globalisation: Who gains when commodities are de-Commodified? International Journal of Technology and Globalisation, v. 1, n. 1, p. 5-28, 1 set. 2004. Disponível em: <https://www.inderscienceonline.com/doi/abs/10.1504/IJTG.2004.004548>. Acesso em: 9 dez. 2019.

Emater-MG (Empresa de Assistência Técnica e Extensão Rural do Estado de Minas Gerais): Balanço Social 2015. Emater-MG, 2015. Disponível em: <http://www.emater.mg.gov.br/doc/site/AEmatermg/Balanco\%20Social.pdf>. Acesso em: 12 out. 2019.

MAPA (Ministério da Agricultura, Pecuária e Abastecimento). Liberações de crédito destinadas a financiamentos ao amparo de recursos do Fundo de Defesa da Economia Cafeeira - FUNCAFÉ Ano base 2015. Disponível em: https://www.gov.br/agricultura/pt-br/assuntos/politicaagricola/cafe/arquivos/liberacoes-de-recursos-do-funcafe-ano-base-2015-posicao31-12-2015.pdf.

MELLO, Fernando Homem. Café brasileiro: não a um novo acordo internacional. Revista de Economia Política, v. 13, n. 4, p. 37-46, 1993. Disponível em: $<$ http://www.rep.org.br/PDF/52-3.PDF>.

MÉNDEZ, V. Ernesto et al. Effects of Fair Trade and organic certifications on smallscale coffee farmer households in Central America and Mexico. Renewable Agriculture and Food Systems, v. 25, n. 3, p. 236-251, 2010. Disponível em: <https://www.cambridge.org/core/journals/renewable-agriculture-and-food-

systems/article/effects-of-fair-trade-and-organic-certifications-on-smallscale-coffeefarmer-households-in-central-america-and-

mexico/FD4FB2E6A77A23543DFA9CA0C4F70523 >. Acesso em: 9 dez. 2019.

MURRAY, Douglas L.; RAYNOLDS, Laura T.; TAYLOR, Peter L. The Future of Fair Trade Coffee: Dilemmas Facing Latin America's Small-Scale Producers. Development in Practice, v. 16, n. 2, p. 179-192, 1 abr. 2006. Disponível em: <https://doi.org/10.1080/09614520600562397>. Acesso em: 9 dez. 2019.

PALHARES et al. Reposicionamento estratégico das indústrias processadoras de café do Brasil: Propostas para sistematização de políticas públicas e estratégias de negócio. Tradução. 1. ed. Brasil: Ministério do Desenvolvimento, Indústria e Comércio Exterior: André Sório, 2015. Disponível em: <http://www.meritos.com.br/livros/144.php>. Acesso em: 9 dez. 2019.

PONTE, Stefano. The "Latte Revolution"? Regulation, Markets and Consumption in the Global Coffee Chain. World Development, v. 30, n. 7, p. 1099-1122, 1 jul. 2002. 
Disponível

em: <http://www.sciencedirect.com/science/article/pii/S0305750X02000323>. Acesso em: 9 dez. 2019.

RUBEN, Ruerd; FORT, Ricardo. The Impact of Fair Trade Certification for Coffee Farmers in Peru. World Development, v. 40, n. 3, p. 570-582, 1 mar. 2012. Disponível em: <http://www.sciencedirect.com/science/article/pii/S0305750X11002051>. Acesso em: 9 dez. 2019.

SPECIALITY COFFEE ASSOCIATION OF AMERICA. SCAA Protocols. Cupping Specialty Coffee. Long Beach: SCAA, 2009. 7 p.

SAES, Maria Sylvia Macchione; SPERS, Eduardo Eugênio. Percepção dos consumidores sobre os atributos de diferenciação do segmento rural: café no mercado interno. Organizações Rurais \& Agroindustriais, v. 8, n. 3, p. 14, 2006.

SILVA, Analice Miranda; DUTRA, Mariana Borges de Lima. Avaliação de informações contidas em rótulos de café torrado e moído. Alimentos e Nutrição Araraquara, v. 22, n. 3, p. 449-454, 2011.

VALKILA, Joni; NYGREN, Anja. Impacts of Fair Trade certification on coffee farmers, cooperatives, and laborers in Nicaragua. Agriculture and Human Values, v. 27, n. 3, p. 321-333, 2010. Disponível em: <https://doi.org/10.1007/s10460-009-9208-7>. Acesso em: 9 dez. 2019.

VEGRO, Celso Luis Rodrigues et al. Restrições à exportação de café torrado e moído. Organizações Rurais \& Agroindustriais, v. 7, n. 2, 2005. Disponível em: <http://revista.dae.ufla.br/index.php/ora/article/view/202>. Acesso em: 9 dez. 2019. 